\title{
Multilevel Fixed Pulse Pattern Control for Medium-Voltage High-Frequency Inverter
}

\author{
Ryuichi Ogawa*a) Member, Masashi Takiguchi* Member, \\ Yugo Tadano* Senior Member
}

(Manuscript received Jan. 14, 2021, revised June 16, 2021)

\begin{abstract}
To satisfy the demand for more compact medium-voltage motor drive systems, it is desirable to increase the frequencies of cascaded H-bridge inverters used in high-speed motor systems. However, in asynchronous pulse-width modulation (PWM) systems, as the output frequency increases, the command voltage and triangular wave carrier frequencies become closer, making it impossible to output the command voltage accurately. This manifests in the form of increased current harmonics, increased surge voltage at the motor terminals, and increased low-frequency ripple current owing to the asynchronous nature of the system. In this study, we adopt a fixed pulse pattern modulation method to address these problems. In our method, a low-distortion output voltage without multiple simultaneous changes is compiled into a table in advance, and subsequently output in synchronization with the fundamental voltage phase. We were able to confirm the effectiveness of the proposed method via simulations and mini-model experiments at fundamental wave frequencies of $700 \mathrm{~Hz}$ and $1000 \mathrm{~Hz}$.
\end{abstract}

Keywords: High Frequency, Multilevel, Pulse Pattern, Decreasing Switching Frequency

\section{Introduction}

Regarding medium-voltage motor drive systems for large capacity fans and pumps, series or parallel connected inverters, open-winding motors, multiphase motors, etc. have been used ${ }^{(1)}$. In particular, medium-voltage multilevel inverters are often used for a few MW systems. Multilevel inverters have the advantage of achieving a high switching frequency of an entire system without increasing the switching frequency of individual semiconductor devices. Further, medium-voltage output is created by summing the output of some low-voltage circuits. Therefore, it is possible to use low-voltage devices and suppress a surge voltage between motor terminals at the switching time.

Modular multilevel converter (MMC) motor drive has been reported as a three-phase motor and multilevel inverter system ${ }^{(2)-}$ (4). MMC is advantageous at the miniaturization point of an entire drive system in applications in which the medium DC voltage can be prepared. However, MMC requires the balance control of capacitor voltages. The difficulty of balance control increases at low output frequencies. Therefore, applying MMC to variable speed drives without complex control is difficult.

Cascaded H-bridge inverter (CHB) is another example of multilevel inverter ${ }^{(5)-(9)}$. CHB comprises series-connected H-bridge inverters and a multiple winding transformer. Since the basic configuration of $\mathrm{CHB}$ is insulated from the input power supply, the safety design is easy. It is also advantageous in that the balance

This paper is based on Reference (42), which published in the International Conference on Electrical Machines and Systems (ICEMS) (2020) (O2020 IEEJ.

a) Correspondence to: Ryuichi Ogawa.

E-mail: ogawa-r@mb.meidensha.co.jp

* MEIDENSHA CORPORATION.

515, Kaminakamizo Higashimakado, Numadu-shi, Shizuoka 410-8588, Japan control of the capacitor voltage, as used in MMC, is unnecessary.

Now, the output voltage generation of the voltage source inverter will be considered. Asynchronous pulse width modulation (PWM) methods, such as carrier-based and space vector modulations, are often used in voltage source inverter. Recently, the methods of decreasing output voltage ripple ${ }^{(10)(11)}$ and DC current ripple (12) have been considered. Especially for multilevel inverter, the PWM method designed for multilevel voltage output has been used. For multilevel, various PWM methods, such as equalization of switching frequency for each semiconductor device (6) (7) and capacitor current control ${ }^{(13)-(15)}$ have been considered.

However, the motor speed has become higher to reduce the size and weight of an entire motor drive system. To increase the motor speed, the output frequency of the inverter should also be increased. In the asynchronous PWM, the carrier frequency is set so that the slope of the carrier becomes larger than the slope of the command voltage to prevent level skipping (multiple simultaneous changes in output voltage level). Therefore, it is necessary to increase the carrier frequency at a high output frequency. The carrier frequency is related to the switching frequency of semiconductor devices, and simply increasing the carrier frequency increases loss.

There are studies of using $\mathrm{SiC}$ as a countermeasure to the problem at high output frequencies. $\mathrm{SiC}$ device is a high-speed switching and low-loss semiconductor device often used to simply improve the efficiency of an inverter ${ }^{(16)}$. This $\mathrm{SiC}$ feature can also be used to achieve a high output frequency. 2-level $(\geq 2.3 \mathrm{kV})^{(17)}$, MMC ${ }^{(18)}$, CHB ${ }^{(19)}$, and 5-level active neutral point clamped (ANPC) inverters (20) (21) have been reported as high output frequency examples of medium-voltage inverter using the $\mathrm{SiC}$ device. However, the cost of the SiC-MOSFET is still higher than that of Si-IGBT. Considering this point, in references (19)-(21), the hybrid configuration of using both SiC-MOSFET and Si-IGBT was proposed, but the increase in the cost is unavoidable compared with 
Si-IGBT only configuration.

Conversely, if we use only Si-IGBT and try outputting highfrequency voltage without increasing carrier frequency, the following three problems will occur.

- Level skipping increases the surge voltage between motor terminals, thereby causing insulation deterioration.

- The number of pulses in one fundamental cycle decreases, thus reducing the expressiveness of the command voltage and increasing current harmonics.

- Ripple current at frequencies below the fundamental frequency occurs due to the asynchronous nature of the triangular wave carrier and the fundamental wave.

In this study, we apply a fixed pulse pattern method to these three problems. The fixed pulse pattern, also called the optimized pulse pattern, is a modulation method in which a low-distorted pulse pattern is derived in advance and the pulse pattern is output in accordance with the voltage phase. The basic theory of the fixed pulse pattern method for 2- or 3-level has been proposed ${ }^{(22)(23)}$, and practical configurations and procedures for industrial applications were proposed relatively recently ${ }^{(24)}{ }^{(25)}$. In some other studies, transient response is discussed. Since the pulse pattern is optimized in one cycle of the fundamental wave, the fixed pulse pattern method is generally inferior to the asynchronous PWM method in the expressiveness of instantaneous voltage changes, which is not a problem for V/f drive in the fan and pump application - the focus of this study. However, for applications that require a transient response, sophisticated measures must be taken. Various controls of the compensation of the pulse pattern have been proposed to improve transient responses (26)-(30). In addition, as evaluation functions other than harmonics, considering the saliency of a motor ${ }^{(31)}$ and iron loss ${ }^{(32)}$ have also been proposed. Further, in multilevel applications, the method for improving the optimization calculation in the case where there are many branches of the pulse pattern ${ }^{(33)}$ ${ }^{(34)}$, the balance control of the capacitor voltage (29) (30) (35)-(37), and implementation using Q-learning ${ }^{(38)}$ have been proposed. There is also a case of dual inverter drive for open-winding motor in which one inverter uses a fixed pulse pattern, and the other compensates remaining harmonic waves ${ }^{(39)}$.

We will recheck the features of the fixed pulse pattern method. In fixed pulse pattern method, a pulse pattern is derived in advance considering canceling harmonic waves in the entire one cycle of the fundamental wave. This feature prevents the increase in harmonic waves, even when the switching frequency is close to the fundamental frequency. Next, in the fixed pulse pattern method, the pulse pattern is output synchronously with the voltage phase. In other words, this is a synchronous PWM method. Therefore, the low-frequency ripple due to the asynchrony does not occur in principle. As a result, it is expected that two of the three problems in high-speed motor drive using asynchronous PWM can be solved from the basic features of fixed pulse pattern method. However, to the best of our knowledge, there is no example of a fixed pulse pattern method that considers level skipping of a line voltage. In reference (1), it is considered that the surge in a motor input voltage causes the insulation breakdown of the motor winding, and it is considered that the surge voltage of more than two times owing to level skipping cannot be ignored.

In this study, we proposed a fixed pulse pattern method especially for multilevel, which can suppress harmonic waves while preventing level skipping. To confirm the effectiveness of the proposed fixed pulse pattern method, we compared the proposed

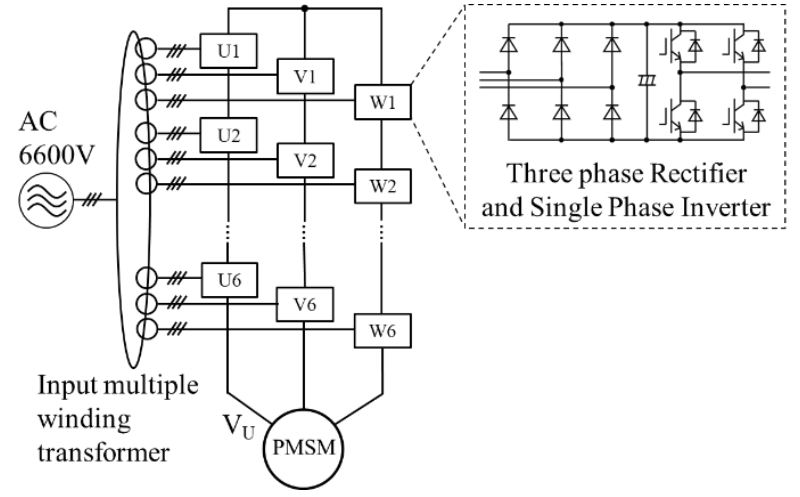

Fig. 1. Cascaded H-bridge inverter.

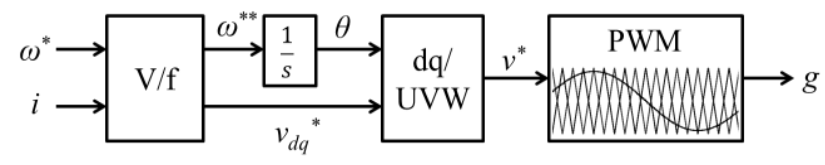

Fig. 2. Control block diagram of asynchronous PWM system (conventional method).

method with the asynchronous PWM method at a fundamental wave frequency of $700 \mathrm{~Hz}$ and $1000 \mathrm{~Hz}$ in simulation and minimodel experiments. When we search for the highest frequency research in multilevel fixed pulse pattern cases ${ }^{(33)-(38)}$, the highest frequency is $380 \mathrm{~Hz}^{(33)}$ in the experimental result and $500 \mathrm{~Hz}^{(37)}$ in the simulation result. The $1000 \mathrm{~Hz}$ result is the highest frequency as a multilevel fixed pulse pattern drive.

\section{Cascaded H-bridge Inverter}

Figure 1 shows the system configuration used in this study. The system uses a cascaded $\mathrm{H}$-bridge inverter with a $6600 \mathrm{~V}$ input to drive a $1.5 \mathrm{MW}$ permanent magnet synchronous motor (PMSM). The $6600 \mathrm{~V}$ three-phase AC input voltage is applied to each cell (U1, U2, .., U6, V1, .., V6, W1, .., W6) through a multiple winding transformer. Each cell is composed of a three-phase rectifier and a single-phase H-bridge inverter. Since the cell outputs are connected in a series by phase, a multilevel output voltage obtained by multiplexing the cell outputs is applied to the motor. In the six-series configuration shown in Fig. 1, the phase voltage $V_{U}$ operates at a maximum of 13 levels.

\section{Modulation Method}

3.1 Asynchronous PWM Figure 2 shows a control block diagram of an asynchronous PWM system (conventional method). Vibration stabilization correction ${ }^{(40)(41)}$ is carried out on the frequency command $\omega^{*}$ by feeding back the detected current $i$ to obtain the corrected frequency command $\omega^{* *}$ and the $\mathrm{dq}$ axis command voltage $v_{d q}{ }^{*}$. In this study, we used V/f control to maintain a fixed, constant ratio between $\omega^{* *}$ and $\left|v_{d q} *\right|$. The control phase $\theta$ is obtained by integrating $\omega^{* *}$, and the three-phase command voltage $v^{*}$ is obtained by dq/UVW conversion using $v_{d q}{ }^{*}$ and $\theta$. In the PWM method, the carrier is compared with the command voltage. Specifically, the gate signal $g$ is generated by comparing the magnitude of $v^{*}$ to triangular wave carrier, the frequency of which is set independently of $\omega^{* *}$.

Figure 3 shows the carrier comparison using the Phase Shift (PS) method. The asynchronous PWM in this study is a PS scheme using 
(a) Comparison

(b) Cell voltage

(c) Phase voltage

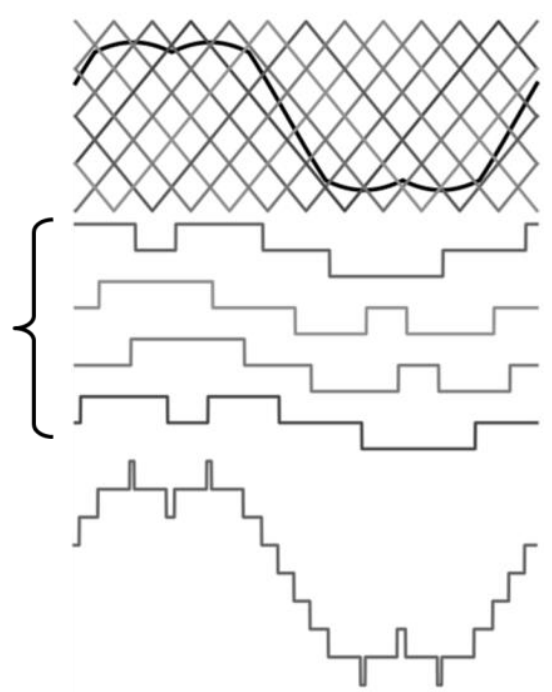

Fig. 3. Carrier comparison using PS method.

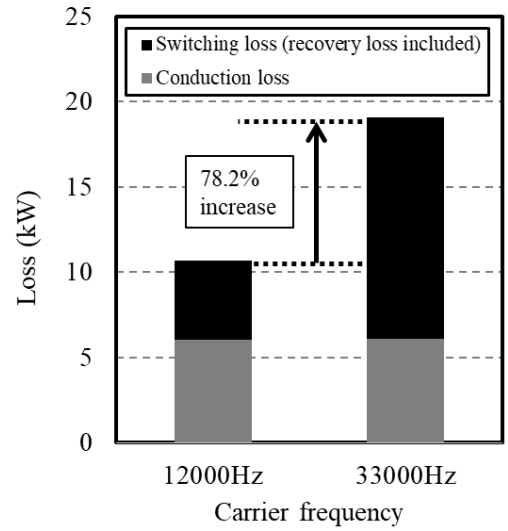

Fig. 4. The estimation of semiconductor loss (13-level CHB, $1.5 \mathrm{MW}, 1000 \mathrm{~Hz}, 120 \mathrm{~A}$ ).

the phase-shifted carrier technique. For simplicity's sake, the figure shows a series of four H-bridge inverters in a phase. In Fig 3(a), one carrier is paired with the same carrier flipped upside-down, to determine the H-bridge inverter output for each cell. The cell outputs are shown in Fig. 3(b). The sum of the cell outputs is the output phase voltage shown in Fig. 3(c). Comparing Fig. 3(a) and Fig. 3(c), it can be seen that the command voltage is expressed as a multilevel output. When using the PS method, in principle, the problem of level skipping in the line voltage can arise. This problem can be addressed by the carrier phase selection (CPS) technique, which selects the carrier by observing the change in command voltage ${ }^{(6)}$.

The condition under which level skipping can be prevented in the CPS method is expressed in Eq. (1). The equation indicates a condition in which the slope of the carrier is greater than the slope of the command voltage. Here, $f_{c}$ is the carrier frequency per cell $(\mathrm{Hz}), f_{r}$ is the command voltage frequency $(\mathrm{Hz})$, and $K$ is the modulation ratio ( 0 to 1$)$ assuming intermediate voltage superposition.

$f_{c}=\frac{\sqrt{3}}{2} \cdot \pi \cdot f_{r} \cdot K$

From Eq. (1), the higher the command voltage frequency $f_{r}$ (that is, the higher the base frequency), the higher the carrier frequency

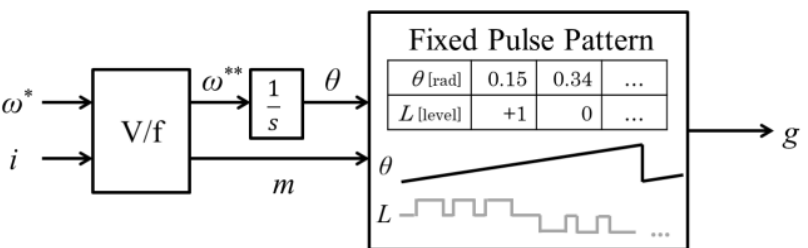

Fig. 5. Control block diagram of fixed pulse pattern system (proposed method).

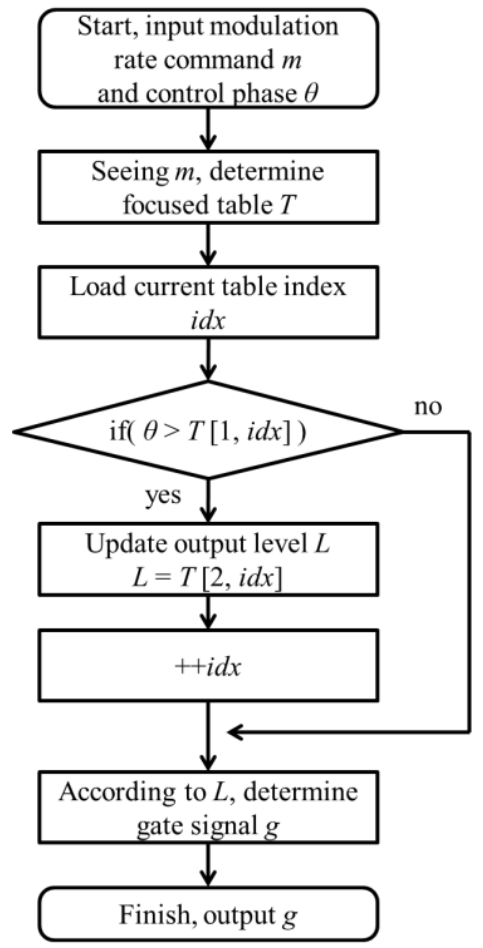

Fig. 6. Table comparison flowchart.

$f_{c}$ needs to be. For example, the maximum voltage $(K=1)$ is output at a fundamental wave frequency of $1000 \mathrm{~Hz}\left(f_{r}=1000\right)$, we have to set carrier frequency to at least $2720 \mathrm{~Hz}\left(f_{c}>2720\right)$. In the $\mathrm{CHB}$ with 6 -series cells, the carrier of an entire inverter is $12 f c$, considering a pair of carriers of an H-bridge inverter. Therefore, the carrier frequency of the entire inverter is at least $32640 \mathrm{~Hz}$.

Figure 4 shows the estimation of semiconductor loss. For CHB with 6-series cells, the IGBT and FWD loss for the entire inverter is calculated. Assuming the rated operation of a $1.5 \mathrm{MW}$ mediumvoltage motor, the maximum modulation rate with cell DC voltage of $850 \mathrm{~V}$, fundamental wave frequency of $1000 \mathrm{~Hz}$, current of 120 $\mathrm{A}_{\mathrm{RMS}}$, and power factor of 1.00 was assumed. Considering that the 13-level drive at $1000 \mathrm{~Hz}$, the switching frequency is at least 12000 Hz. Therefore, 12000 and $33000 \mathrm{~Hz}$ are compared. At $33000 \mathrm{~Hz}$ result, the switching loss is enormous, and the loss increases by 8.4 $\mathrm{kW}$. Based on the $12000 \mathrm{~Hz}$ result, the loss increase ratio is $78.2 \%$, which means that the easy measure of the increase in carrier frequency is not allowed in the high-speed motor drive system.

In an asynchronous PWM system, the carrier and fundamental wave frequencies are set independently. Therefore, depending on the frequency of a fundamental wave, the number of pulses in one cycle of the fundamental wave changes every few cycles. At this time, ripple occurs at frequencies below the fundamental frequency, 


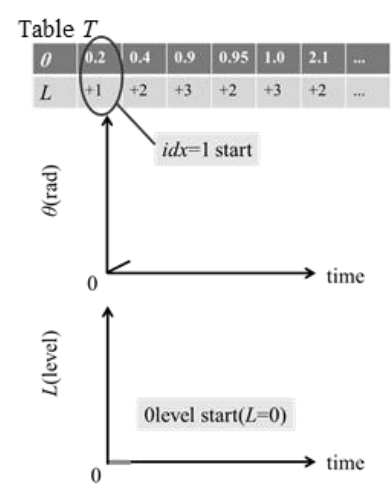

(a)

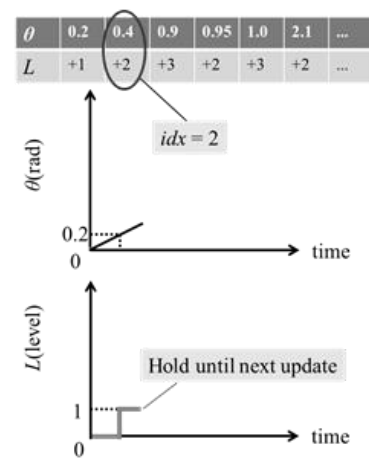

(c)

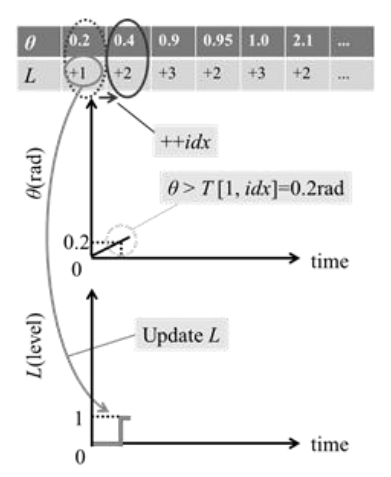

(b)

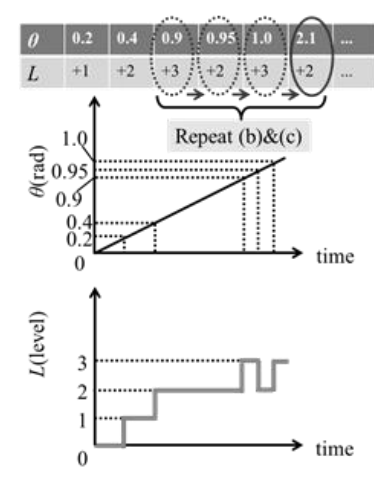

(d)
Fig. 7. Table comparison actions and output voltage levels.

depending on the change frequency in the number of pulses.

3.2 Fixed Pulse Pattern Figure 5 shows a control block diagram of the fixed pulse pattern system (our proposed method). The V/f control is similar to the asynchronous PWM method shown in Fig. 2. However, the difference is that the output is the modulation rate command $m$. After the V/f control, the $\mathrm{dq} / \mathrm{UVW}$ conversion is not performed. Instead, the modulation rate command $m$ is used to decide which table is to be referenced, and the gate signal $\mathrm{g}$ is generated from the value in the table corresponding to the control phase $\theta$. Each value in the table is determined in advance, using the pulse pattern derivation shown in Section 4.

Figure 6 shows the table comparison flowchart. In this flowchart, the modulation rate command $m$ is used to determine the table $T$ to be referenced, and the output level $L$ is determined by comparing $T$ to the control phase $\theta$. Then, based on the circuit configuration in Fig. 1, the gate signal $g$ for output level $L$ is determined. These actions make it possible to output the pulse patterns in the table in accordance with the voltage phase. However, $L$ is the phase voltage level after multiplexing the cell unit outputs (equivalent to $\mathrm{V}_{\mathrm{U}}$ in Fig. 1). Tables are created for each pulse pattern in increments of a few percent to 0.1 percent across the range of modulation rates to be used, and the table with the modulation rate closest to $m$ is used as the table $T$.

Figure 7 shows the table comparison of the actions shown in Fig. 6. Here, $i d x$ is the index of the table reference position, and $L$ is the output phase voltage level. The initial values are set to $i d x=1, L=$ 0 . The first row of table $T$ contains the phase information $\theta$ of the pulse pattern, and the second row contains the level information $L$.
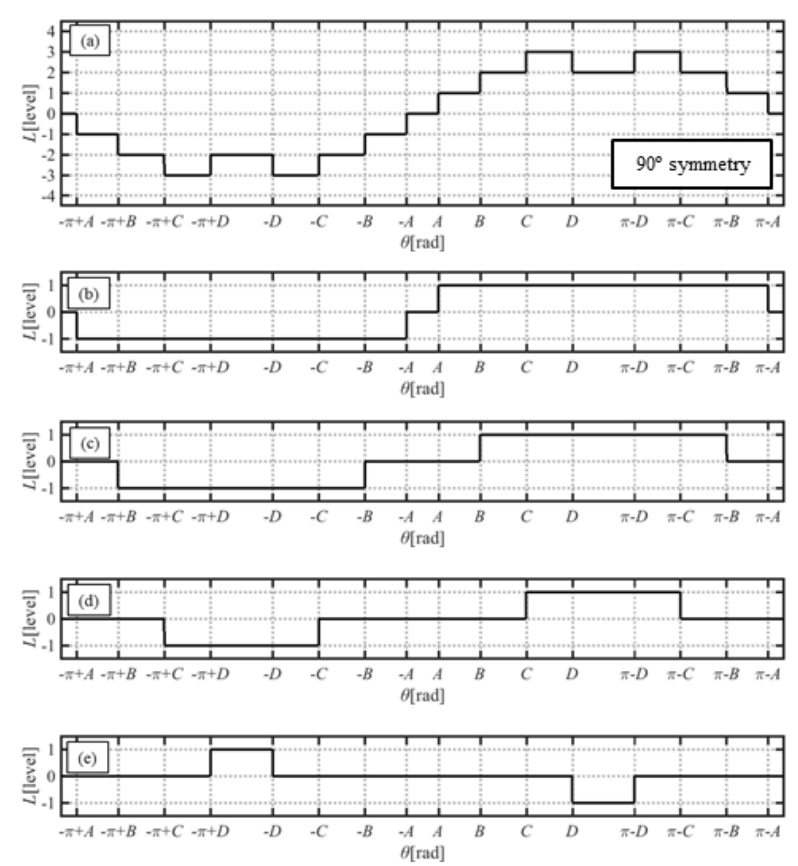

Fig. 8. Pulse pattern example.

In Fig. 7(a), since $\theta$ is smaller than the phase value of $0.2 \mathrm{rad}$ at $i d x$ $=1$ in table $T$, the output is kept at $L=0$. In Fig. 7(b), $\theta$ increases and becomes larger than $0.2 \mathrm{rad}$, so $L$ is updated to the +1 level at $i d x=1$. After the update, $i d x$ is incremented. In Fig. 7(c), although $\theta$ has increased above Fig. 7(b), the phase value of $0.4 \mathrm{rad}$ at $i d x=$ 2 has not been reached, so $L$ is held at the +1 . In Fig. 7(d), further updates and holds are repeated. Looking at the plot of $L$, it can be seen that it follows the pulse pattern specified in the table layout.

\section{Pulse Pattern Design}

In the asynchronous PWM system, the triangular wave carrier and the command voltage are compared to determine the voltage pulse width at which it is possible to output the command voltage by averaging one cycle of the triangular wave. In other words, the asynchronous PWM method is based on the period of the triangular wave and does not necessarily generate optimal pulses from the perspective of one cycle of the fundamental output voltage wave. Therefore, when the carrier frequency approaches the fundamental frequency, and the number of pulses in one cycle of the fundamental wave decreases, the expressiveness of the command voltage decreases and the distortion of the output voltage increases.

In contrast, in the fixed pulse pattern method, the pulse pattern is optimized in advance based on one cycle of the fundamental wave. Therefore, even if the number of pulses in one fundamental wave cycle is small, an output voltage with low distortion can be obtained. The method of designing pulse patterns with low distortion is described below.

Figure 8 shows an example of a pulse pattern. To illustrate a shape that synchronizes with the fundamental wave with sinusoidal symmetry, we assume a pulse pattern that is symmetrical every $90^{\circ}$, as shown in Fig. 8(a).

Here, we examine the pulse pattern distortion using the Fourier series expansion. Figure 8(a) can be decomposed into three level pulse patterns that are symmetric every $90^{\circ}$. The decomposition results are indicated in Figs. 8(b) through 8(e). After decomposition, 
the Fourier series expansion of the pulses is determined and added together.

When Fig. 7(b) is expanded by the Fourier series, Eq. (5) is obtained via Eqs. (2), (3), and (4). Here $a_{0}, a_{n}$, and $b_{n}$ are Fourier coefficients, $N$ is the number of cascaded cell units, and $f_{A}(\theta)$ is the Fourier series representation of (b). The voltage level is normalized at the maximum level.

$$
\begin{gathered}
a_{0}=\frac{1}{\pi N}\left\{\int_{-\pi}^{-\pi+A} 0 d x+\int_{-\pi+A}^{-A}-1 d x+\int_{-A}^{A} 0 d x+\int_{A}^{\pi-A} 1 d x\right. \\
\left.+\int_{\pi-A}^{\pi} 0 d x\right\}=0
\end{gathered}
$$$$
a_{n}=\frac{1}{\pi N}\left\{\int_{-\pi}^{-\pi+A} 0 \cdot \cos (n x) d x+\int_{-\pi+A}^{-A}-1 \cdot \cos (n x) d x\right.
$$$$
+\int_{-A}^{A} 0 \cdot \cos (n x) d x+\int_{A}^{\pi-A} 1 \cdot \cos (n x) d x
$$$$
\left.+\int_{\pi-A}^{\pi} 0 \cdot \cos (n x) d x\right\}
$$$$
=0 \quad(n=1,2,3,4, \ldots)
$$

$b_{n}=\frac{1}{\pi N}\left\{\int_{-\pi}^{-\pi+A} 0 \cdot \sin (n x) d x+\int_{-\pi+A}^{-A}-1 \cdot \sin (n x) d x\right.$

$$
\begin{gathered}
\quad+\int_{-A}^{A} 0 \cdot \sin (n x) d x+\int_{A}^{\pi-A} 1 \cdot \sin (n x) d x \\
\left.\quad+\int_{\pi-A}^{\pi} 0 \cdot \sin (n x) d x\right\} \\
= \begin{cases}\frac{4}{n \pi N} \cos (n A) & (n=1,3,5,7, \ldots) \\
0 & (n=2,4,6,8, \ldots)\end{cases} \\
f_{A}(\theta)=\frac{a_{0}}{2}+\sum_{n=1}^{\infty}\left\{a_{n} \cos (n \theta)+b_{n} \sin (n \theta)\right\} \\
=\frac{4}{\pi N}\left\{\cos A \sin \theta+\frac{1}{3} \cos (3 A) \sin (3 \theta)\right. \\
\left.\quad+\frac{1}{5} \cos (5 A) \sin (5 \theta)+\cdots\right\}
\end{gathered}
$$

Since sinusoidal symmetry was assumed in Fig. 8(a), Eq. (5) eliminates the cosine and even-order harmonic components. We make the same calculations for Figs. 8(c) through 8(e), adding all of them together. The $n$th order harmonic amplitude $H_{n}$ of the pulse pattern in Fig. 8(a) is then obtained, as expressed in Eq. (6). Since the level of changes in Fig. 8(e) are in the opposite direction to Figs. 8(b), (c), and (d), the term for $D$ in Eq. (6) has a negative sign.

$H_{n}=\left|\frac{4}{n \pi N}\{\cos (n A)+\cos (n B)+\cos (n C)-\cos (n D)\}\right|$

$$
(n=1,3,5,7, \ldots)(6)
$$

Harmonics $H_{3}, H_{5}, H_{7}, \ldots$ (excluding $H_{1}$ ) of the fundamental wave amplitude are the distortion components of the voltage to be output. In other words, the smaller the values of $H_{3}, H_{5}, H_{7}, \ldots$, the lower the distortion of the pulse pattern.

The $n$th order harmonic amplitude can be calculated as described above, even when there are changes in the number of switching operations or the direction of individual level changes.

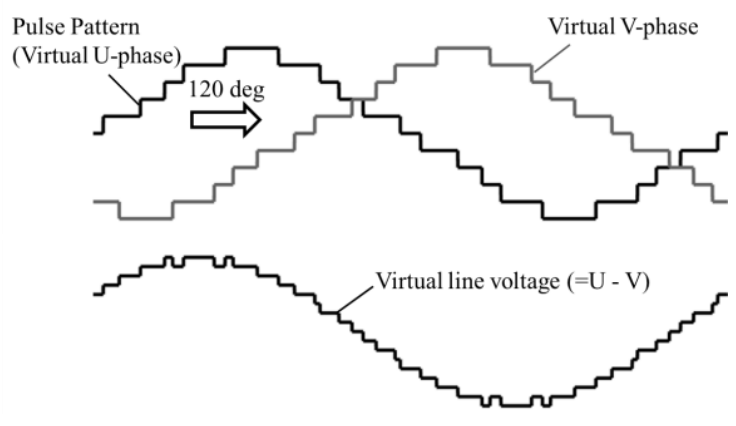

Fig. 9. Consideration of virtual line voltage.

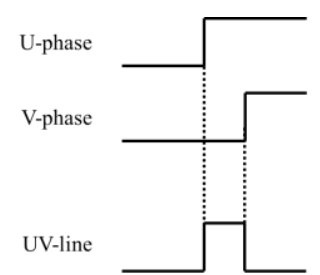

(a)

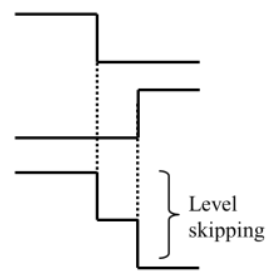

(c)

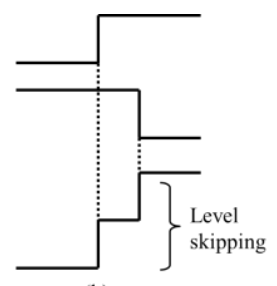

(b)

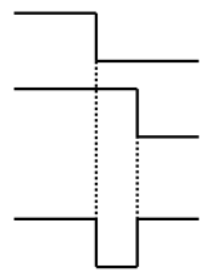

(d)
Fig. 10. Relationship between the phase voltage changes and the line voltage change.

Below, we examine an evaluation function for pulse pattern derivation calculation using Eq. (6). The evaluation function is based on a previous report in reference (24).

First, to obtain the fundamental voltage wave corresponding to the modulation rate command $m$, Eq. (7) must be observed.

$$
m=\frac{4}{\pi N}(\cos A+\cos B+\cos C-\cos D)
$$

Next, the phases of each level change $(A, B, C, D)$ should be designed in such a way that no level skipping occurs. This can be performed by determining the phase width $\theta_{s}$ in radians between the level changes, based on Eq. (8). Here, $t_{\text {skip }}$ is the maximum time width (s) that can be considered a pseudo level skipping, and $f_{\text {out }}$ is the fundamental frequency $(\mathrm{Hz})$ at which the pulse pattern is to be used.

$$
\theta_{s}>2 \pi \cdot f_{\text {out }} \cdot t_{\text {skip }}
$$

Notably, the pulse pattern in Fig. 8 was designed for phase voltage. Even if level skipping was prevented in the phase voltage, level skipping might occur at the line voltage depending on the relationship between the switching timings of other phases. In this study, the level skipping of the line voltage was also evaluated.

Figure 9 shows the consideration of virtual line voltage. Generally, three-phase equilibrium is assumed in motor drives. Based on this thought, the pulse pattern in Fig. 8 was assumed to be the virtual U-phase, and the pulse pattern shifted by $120^{\circ}$ was assumed to be the virtual V-phase. Then, the virtual line voltage was calculated from the virtual U- and V-phases. The switching 
phases of not only the phase voltage shown in Fig. 8 but also the virtual line voltage were designed to maintain the phase width of Eq. (8). In the virtual line voltage, the widths of all switching phases need not be restricted. Whether the phase width was required depended on the sign of the voltage change.

Figure 10 shows the relationship between the phase voltage changes of the two phases and the line voltage change. When the phase width of the phase voltage changes was small, there were four types of change patterns of the line voltage according to the direction of the phase voltage change. If the $\mathrm{U}$ - and V-phases change with the same sign as in Figs. 10(a) and 10(c), the line voltage is not considered to be level skipping. Therefore, Eq. (8) need not be satisfied. Meanwhile, when the U- and V-phases change in the opposite sign as in Figs. 10(b) and 10(d), the line voltage is considered to be level skipping. In this case, the phase width should be designed to maintain Eq. (8). However, Eq. (8) not only prevents level skipping but also serves to secure the physical switching time of the semiconductor device. Therefore, we can also choose a design policy that adheres to Eq. (8) regardless of the signs of adjacent voltage changes.

From the condition of the phase width of switching, the maximum frequency of multilevel fixed pulse pattern method could be obtained. One cycle of the fundamental wave must be longer than the time it takes for each phase to output the maximum level pulse pattern while keeping the time width $t_{\text {skip }}$ between the level changes. Therefore, the fundamental frequency $f_{\text {out }}$ was restricted by Eq. (9). $P$ is the number of phases in the system and $N$ is the maximum level. Here $4 N$ indicates the minimum number of switching of each phase in one fundamental cycle when outputting the maximum level AC voltage. Since Eq. (9) is the theoretical limit of the maximum level switching, it is necessary to drive at a frequency sufficiently lower than Eq. (9), considering outputting the voltage corresponding to the modulation rate command.

$$
f_{\text {out }}<\frac{1}{4 N \cdot P \cdot t_{\text {skip }}}
$$

Regarding harmonics, the goal is to reduce the harmonics of the current. As long as the voltage is balanced across the three phases, voltage harmonics that are multiples of three do not affect the motor current. For this reason, voltage harmonics such as $n=3,6,9, \ldots$ can be ignored, while $n=5,7,11,13, \ldots$ must be taken into account. The aim is to reduce the lower-order voltage harmonics, since the inductance component of the motor ensures that the higher-order voltage harmonics do not affect the current. Therefore, Eq. (10) is the conditional expression for the harmonic currents. In this equation, the $n^{2}$ in the denominator of the coefficient takes into account the inductance component.

$$
\begin{array}{r}
\left|\frac{4}{n^{2} \pi N}\{\cos (n A)+\cos (n B)+\cos (n C)-\cos (n D)\}\right| \\
(n=5,7,11,13,17, \ldots)
\end{array}
$$

Based on the above, under the conditions expressed in Eqs. (7) and (8), we search for combinations of phases $A, B, C$, and $D$ that reduce Eq. (10) as much as possible. After finding $A, B, C$, and $D$, the pulse pattern for one cycle of the fundamental wave is determined from the symmetry of the pulse pattern. In this way, it is possible to derive a pulse pattern that is based on one cycle of the fundamental wave, in which there is no level skipping in voltage and the current harmonics are small.

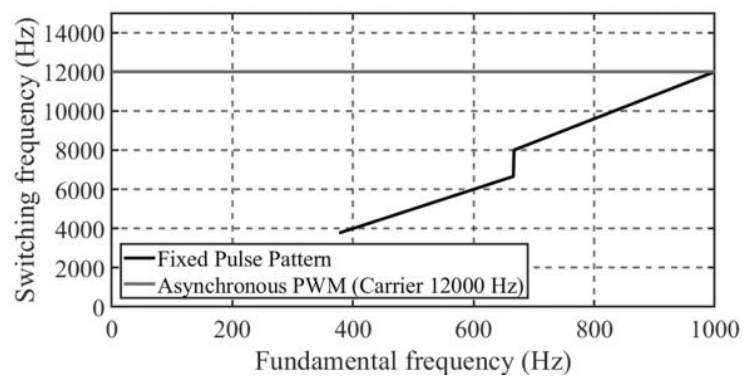

Fig. 11. Relationship between fundamental frequency and switching frequency.

Notably, Eqs. (8), (9), and (11) are nonlinear optimizations. In this optimization, it is difficult to derive the optimal pulse pattern when the number of switching in one cycle is large. Further, the frequency of the low-order harmonic wave at a high frequency corresponded to the high-order harmonic wave at a low frequency. Therefore, we should increase the number of switching to reduce current ripple sufficiently in the low-frequency region with respect to the rated frequency, which means that it is difficult to derive a pulse pattern for low frequencies. However, motor drive systems for fans and pumps were handled in this study. Generally, the higher the frequency, the greater the load, so the design restriction is in the high-frequency range. Therefore, the conventional asynchronous PWM method is used in the low-frequency range, and the fixed pulse pattern method is used in the medium- to high-frequency range.

\section{Simulation Result}

To confirm the effectiveness of the fixed pulse pattern method, we ran a motor drive simulation to compare it to the conventional asynchronous PWM method.

Figure 11 shows the relationship between fundamental and switching frequencies. Since the proposed fixed pulse pattern method is the voltage synchronized switching, the switching frequency increases proportionally with the fundamental frequency. The part where the switching frequency becomes a step in the vicinity of $650 \mathrm{~Hz}$ is a border to reduce the number of switching in $1 / 4$ cycle, which means the number of variables of pulse pattern design, from six to five. In addition, the asynchronous PWM method is used for the region where the line of switching frequency does not exist. The carrier frequency of the asynchronous PWM method is set to $12,000 \mathrm{~Hz}$ in the whole inverter. This is equivalent to that of the fixed pulse pattern method at the fundamental wave frequency of $1000 \mathrm{~Hz}$.

For preventing level skipping, the minimum time width between switching is set to $7 \mu$ s, comprising dead-time of $5 \mu$ s and buffer time of $2 \mu \mathrm{s}$. Eq. (11) is a case where $t_{\text {skip }}=7 \times 10^{-6}, N=6, P=3$ in Eq. (9). As a result, the frequency upper limit was found to be 1984 $\mathrm{Hz}$, indicating that level skipping prevention had a sufficient margin with respect to the fundamental wave frequency of $1000 \mathrm{~Hz}$.

$$
\begin{aligned}
f_{\text {out }}<\frac{1}{4 N \cdot P \cdot t_{\text {skip }}} & =\frac{1}{4 \cdot 6 \cdot 3 \cdot 7 \times 10^{-6}} \\
& =1984.13
\end{aligned}
$$

Figure 12 shows the simulation results at a fundamental wave of $1000 \mathrm{~Hz}$. We set the distortion factor (THD) based on the analysis of the U-phase current, by first obtaining the results of the discrete 

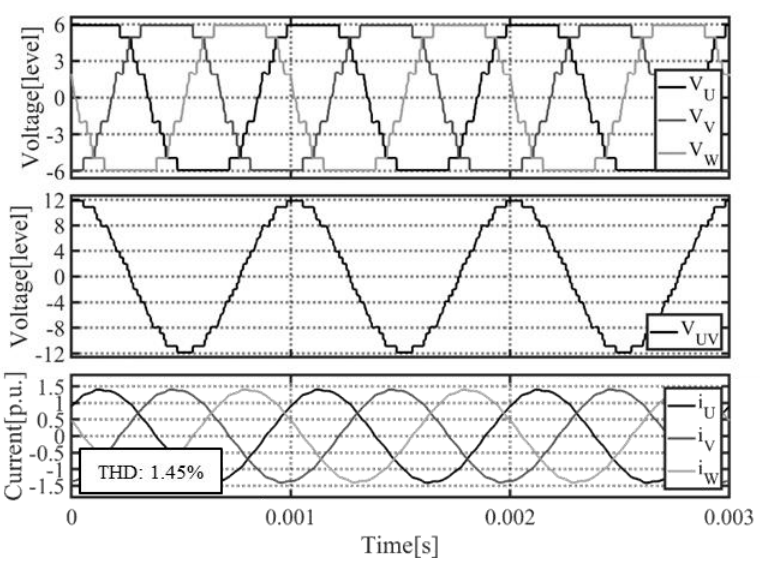

(a) Fixed pulse pattern method (proposed method)
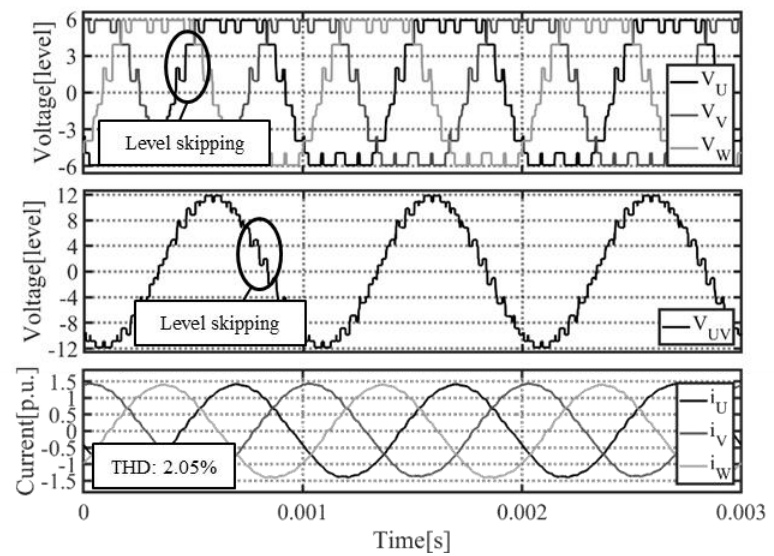

(b) Asynchronous PWM method (conventional method)

Fig. 12. Simulation results at fundamental wave of $1000 \mathrm{~Hz}$.

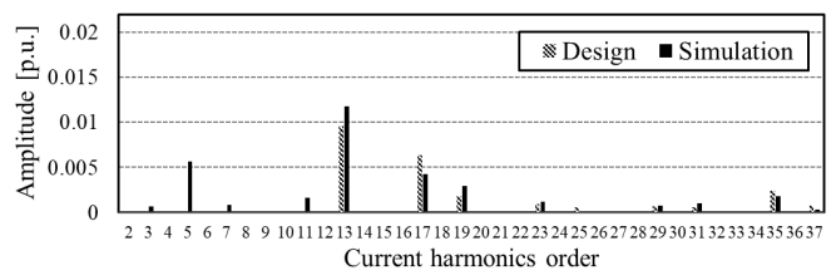

Fig. 13. Comparison between the pulse pattern design and simulation result at $1000 \mathrm{~Hz}$ simulation.

Fourier transform (DFT) in increments of $5 \mathrm{~Hz}$, and then taking the square root of the sum of the squares of all components with frequencies higher than the fundamental frequency. In the asynchronous PWM voltage waveform shown in Fig. 12(b), the number of pulses is reduced and the shape is asymmetric in terms of positives and negatives. In contrast, the fixed pulse pattern method in Fig. 12(a) maintains symmetry. The effect of this is that the current THD is smaller in Fig. 12(a).

When the carrier frequency is set to $12,000 \mathrm{~Hz}$ and the fundamental frequency to $1000 \mathrm{~Hz}$, Eq. (1) is not satisfied if the maximum modulation rate is used. As a result, in the voltage waveform in Fig. 12(b), level skipping occurs in the output voltage near the zero crossing where the slope of the command voltage is large. Level skipping increases the surge voltage of the motor, which is why filtering and other measures are necessary. In Fig. 12(a), neither the phase voltage nor the line voltage caused level skipping.

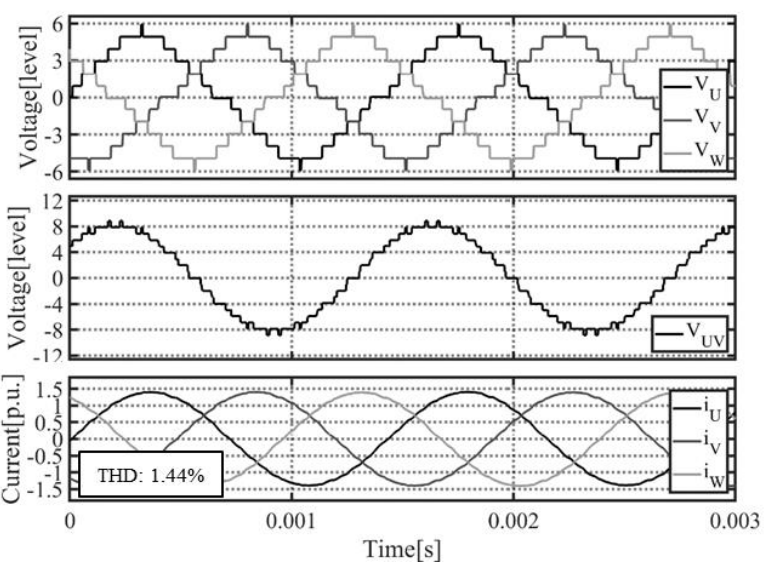

(a) Fixed pulse pattern method (proposed method)

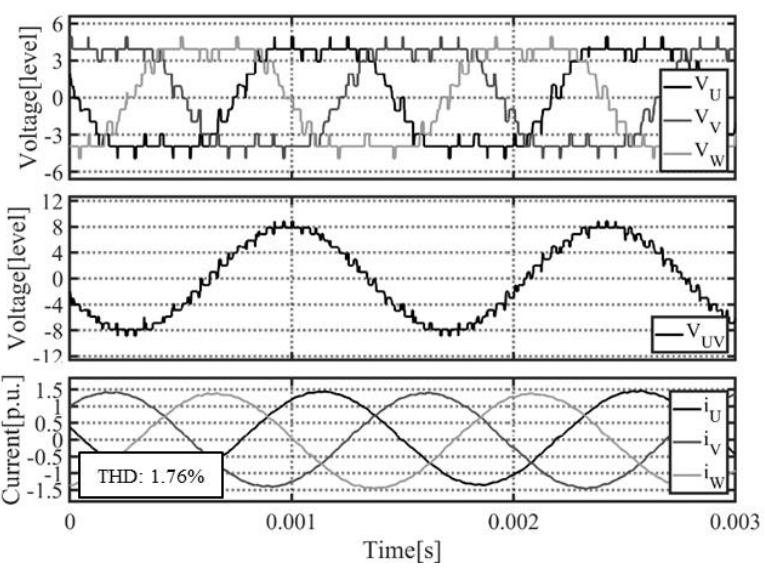

(b) Asynchronous PWM method (conventional method)

Fig. 14. Simulation results at fundamental wave of $700 \mathrm{~Hz}$.

Figure 13 shows the comparison between the pulse pattern design and simulation result. The current harmonics were calculated from the voltage harmonics of the designed pulse pattern table considering the motor. The results were normalized so that the fundamental frequency component would be 1.0. It was confirmed that the tendency of design and simulation were close. There was a difference between the design and simulation, especially in the low order, which was considered to be owing to the discretization error of the control and dead-time.

Figure 14 shows the simulation results at a fundamental wave of $700 \mathrm{~Hz}$. The THD is smaller in Fig. 14(a). The $700 \mathrm{~Hz}$ fundamental wave is not an integer multiple of the $12,000 \mathrm{~Hz}$ carrier, so in the asynchronous PWM system, the number of pulses per cycle of the fundamental wave varies from cycle to cycle. Looking near the positive peak of $\mathrm{V}_{\mathrm{U}}$ in Fig. 14(b), it can be seen that the number of pulses varies in cycles 1 and 2 . This caused the magnitude of the iu peak in each cycle. In other words, in the current in Fig. 14(b), ripple occurs at frequencies below the fundamental frequency.

Figure 15 shows the results of the DFT of the U-phase current at a fundamental wave of $700 \mathrm{~Hz}$. The results are normalized so that the fundamental frequency component would be 1 . Figure 15 shows the frequency components of the current. In the asynchronous PWM method results, the spectrum is active at $100 \mathrm{~Hz}$ and $200 \mathrm{~Hz}$, which are below the $700 \mathrm{~Hz}$ frequency of the fundamental wave. Hence, the DFT results also confirm that Fig. 15(b) contains lowfrequency components. In contrast, there is no low frequency ripple in the fixed pulse pattern method. This is because, under this 


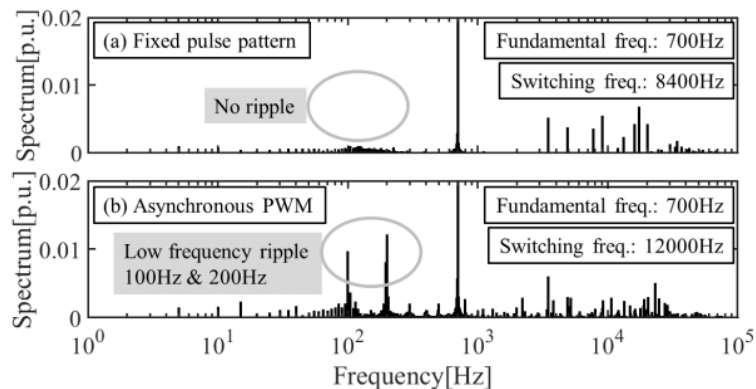

Fig. 15. Results of discrete Fourier transform of U-phase current at $700 \mathrm{~Hz}$ simulation.

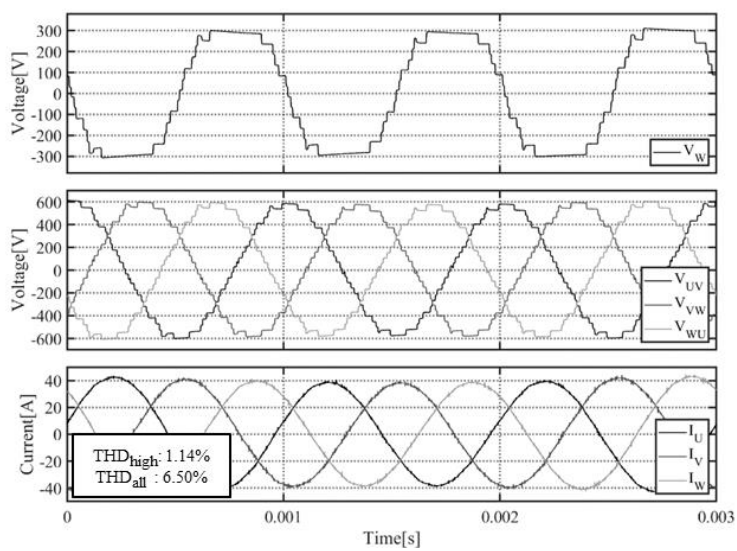

(a) Fixed pulse pattern method (proposed method)
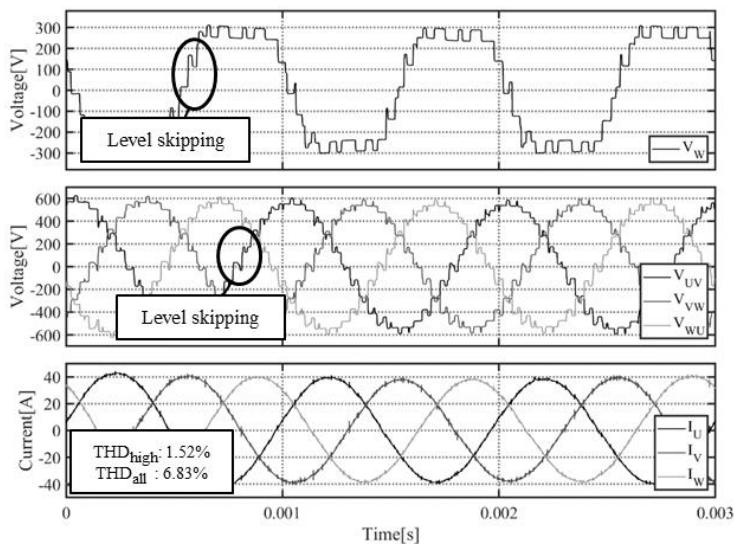

(b) Asynchronous PWM method (conventional method)

Fig. 16. Mini-model experimental results at fundamental wave of $1000 \mathrm{~Hz}$.

method, the output voltage is synchronized with the fundamental voltage phase. The proposed fixed pulse pattern method has higher current harmonics than the asynchronous PWM method in some orders, which is the result of giving the highest priority to the prevention of level skipping in the phase and the line voltage. As shown in Figs. 12 and 14, the current THD, that is, the total harmonics, is smaller in the fixed pulse pattern method even though these THD values are not include the low frequency ripple such as at $100 \mathrm{~Hz}$ and $200 \mathrm{~Hz}$.

\section{Experimental Result}

The effectiveness of the fixed pulse pattern method was verified via a mini-model experiment.

A three-phase AC power supply $(400 \mathrm{~V}, 50 \mathrm{~Hz})$ was input to CHB
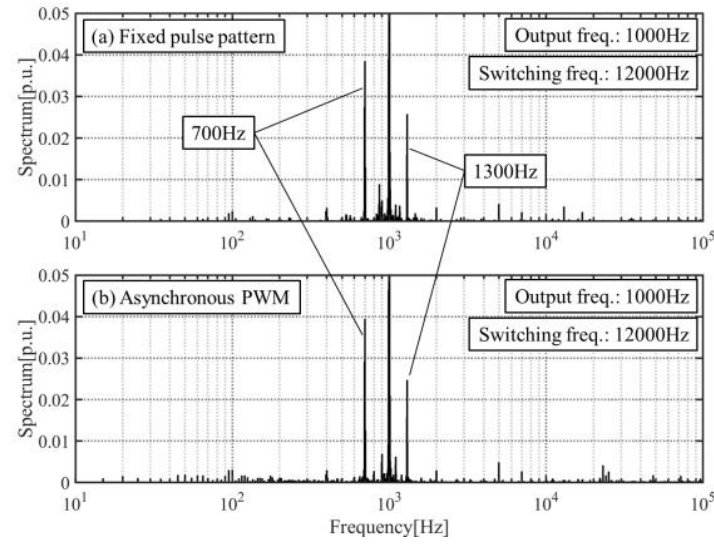

Fig. 17. Results of FFT of U-phase current at $1000 \mathrm{~Hz}$ experiment.

of 6-series configuration, and the inverter output was connected to $15 \mathrm{~kW}, 28 \mathrm{~A}, 1000 \mathrm{~Hz}$ PMSM. The number of levels of the inverter was 13 , which was the same as the actual medium-voltage system. The design of the switching frequency was the same as in Fig. 11 of Section 5. The fixed pulse pattern method was used from approximately $400 \mathrm{~Hz}-40 \%$ of the rated frequency - and the asynchronous PWM method was used for frequencies lower than that.

In actual control, it is necessary to compare the control phase and the table phase of a pulse pattern at a sufficiently high speed with respect to the fundamental wave cycle. In this mini-model, we used a field programmable gate array (FPGA) of a $30 \mathrm{MHz}$ clock. The table comparison was processed in 5 clocks. Therefore, the table comparison was performed at $6 \mathrm{MHz}$, and the resolution for one cycle of the fundamental wave of $1000 \mathrm{~Hz}$ was 6000 frequency division.

In the mini-model experiment, in addition to the line voltage and phase current, the output of the phase from the neutral point of the inverter, that is, the phase voltage, was measured for clarity of the pulse pattern. The phase voltage was measured only in the W-phase due to the problem of the experimental configuration.

Figure 16 shows the results of $1000 \mathrm{~Hz}$. W-phase voltage, the line voltage, and phase current are shown in order from the top. The fixed pulse pattern method achieved $1000 \mathrm{~Hz}$ drive while suppressing the switching frequency. Level skipping occurred in the asynchronous PWM method but not in the proposed fixed pulse pattern method. Notably, voltage changes of about half of the voltage level, such as at +5 levels of $V_{w}$, could be seen, which was because the voltage difference between the collector-emitter voltage and diode voltage of the IGBT occurred when the current polarity was reversed. Since the IGBTs were six series, the sum of the voltage was about half the level. This problem is considerably mitigated and can be ignored in actual medium-voltage systems with higher DC voltages, as in the simulation in Section 5.

With respect to the current in Fig. 16, ripples over multiple periods of the fundamental wave were observed in Figs. 16(a) and 16(b). Then, the frequency components were observed by Fourier transform.

Figure 17 shows the fast Fourier transform (FFT) result of the Uphase current at $1000 \mathrm{~Hz}$. There were ripple components at $700 \mathrm{~Hz}$ and $1300 \mathrm{~Hz}$ in Figs. 17(a) and 17(b). This ripple could be rephrased as the ripple of fundamental frequency $\pm 300 \mathrm{~Hz}$ and was due to a DC voltage ripple. 


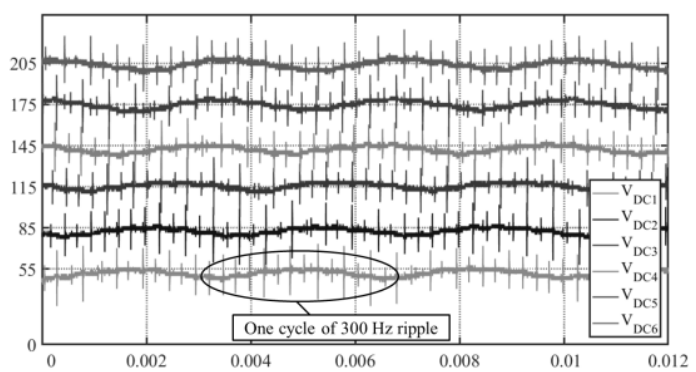

Fig. 18. DC voltage of the W-phase cells at $1000 \mathrm{~Hz}$, $70 \%$ torque drive.

Figure 18 shows the DC voltage of the W-phase cells at $1000 \mathrm{~Hz}$, $70 \%$ torque drive. The cell voltage waveforms were offset by $30 \mathrm{~V}$ for clarity. It can be seen a ripple in DC voltage. The frequency of this DC ripple was $300 \mathrm{~Hz}$, which was six times the power supply frequency of $50 \mathrm{~Hz}$ and the typical frequency of the three-phase rectifier ripple. This ripple was so large as not to be ignored with respect to the average DC voltage that components of amplitude modulation were added to the cell output.

Since the current ripple due to DC voltage was not directly related to the current distortion of two modulation methods, we confirmed THD with two values; THD high which considered only the component of higher frequency than the fundamental frequency $+300 \mathrm{~Hz}$, and $\mathrm{THD}_{\text {all }}$ which considered the all component, except for the fundamental wave itself.

As shown in Fig. 16, for $\mathrm{THD}_{\text {high, }}$ the fixed pulse pattern of Fig. 16(a) was $1.14 \%$, and the asynchronous PWM of Fig. 16(b) was $1.52 \%$. For $\mathrm{THD}_{\text {all }}$, the former was $6.50 \%$, the latter was $6.83 \%$. Therefore, whether the current ripple due to DC voltage ripple was included, the proposed fixed pulse pattern method resulted in smaller current distortion.

Figure 19 shows the results of $700 \mathrm{~Hz}$. Although the fixed pulse pattern had a lower switching frequency than the asynchronous PWM, it had smaller for both THDhigh and THDall.

Figure 20 shows the FFT result of the U-phase current at $700 \mathrm{~Hz}$. There were ripples at $400 \mathrm{~Hz}$ and $1000 \mathrm{~Hz}$ in Figs. 20(a) and 20(b), which were due to the $300-\mathrm{Hz}$ DC voltage ripple. In addition, in the vicinity of $100 \mathrm{~Hz}$ and $200 \mathrm{~Hz}$, both methods have components. We think these are mainly caused by the asynchrony of the fundamental wave and DC $300 \mathrm{~Hz}$ ripple, but the fixed pulse pattern had smaller values. This suggests the fixed pulse pattern method did not suppress ripples due to DC voltage asynchrony but suppressed ripples due to switching asynchrony.

\section{Conclusion}

When cascaded H-bridge inverters are made at higher frequency, three problems arise in the asynchronous PWM system: increased motor surge voltage, increased current harmonics, and increased low-frequency ripple current. We solved these problems by using the fixed pulse pattern method.

At a fundamental wave frequency of $1000 \mathrm{~Hz}$, the current THD was smaller than under the asynchronous PWM method, and there was no level skipping of the output voltage. The effectiveness of low-frequency ripple reduction was confirmed by simulation. In the mini-model experiment, the decrease of ripple due to asynchrony was seen, but the ripples of the fundamental frequency $\pm 300 \mathrm{~Hz}$ were generated, which was due to DC voltage ripple, and we need
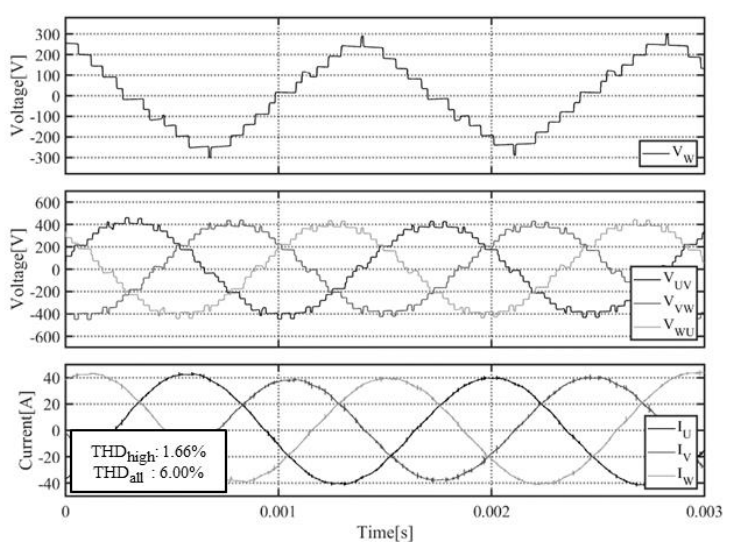

(a) Fixed pulse pattern method (proposed method)
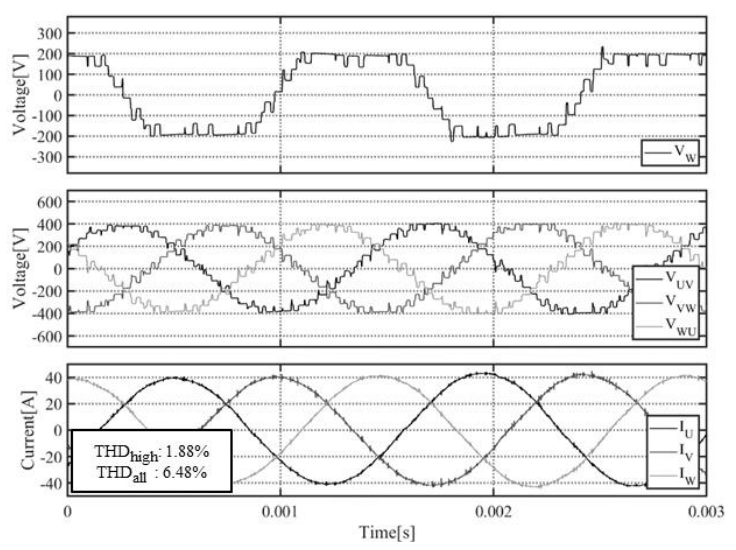

(b) Asynchronous PWM method (conventional method)

Fig. 19. Mini-model experimental results at $700 \mathrm{~Hz}$.
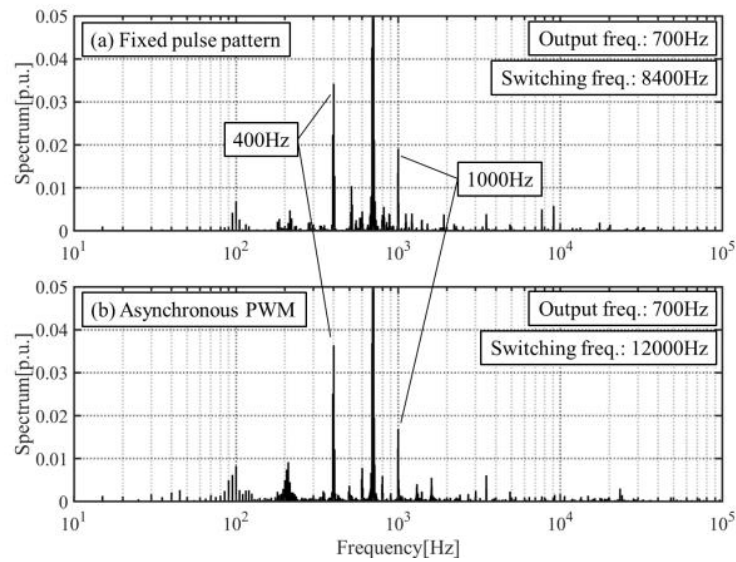

Fig. 20. Results of FFT of U-phase current at $700 \mathrm{~Hz}$ experiment.

to consider the capacitance of the DC link capacitor in the future application to medium-voltage system.

The maximum frequency of multilevel fixed pulse pattern research ${ }^{(33)-(38)}$ is $500 \mathrm{~Hz}$, and the $1000 \mathrm{~Hz}$ result of this paper is the highest case, to the best of our knowledge. This suggests the possibility of applying the proposed fixed pulse pattern method to high-frequency multilevel inverters and the usefulness of the method in high-speed medium-voltage motor drive systems. 


\section{References}

(1) L. Ben-Brahim, A. Gastli, T. Yoshino, T. Yokoyama, and A. Kawamura, "Review of Medium Voltage High Power Electric Drives", IEEJ J. Ind. Appl., Vol. 8, No. 1, pp. 1-11 (2019)

(2) M. Hagiwara, K. Nishimura, and H. Akagi, "A Medium-Voltage Motor Drive With a Modular Multilevel PWM Inverter", IEEE Trans. Power Electron., Vol. 25, No. 7, pp. 1786-1799 (2010)

(3) S. Debnath, J. Qin, B. Bahrani, M. Saeedifard, and P. Barbosa, "Operation, Control, and Applications of Modular Multilevel Converter: A Review", IEEE Trans. Power Electron., Vol. 30, No. 1, pp. 37-53 (2015)

(4) A. Antonopoulos, L. Ängquist, S. Norrga, K. Ilves, L. Harnefors, and H. Nee, "Modular Multilevel Converter AC Motor Drives With Constant Torque From Zero to Nominal Speed", IEEE Trans. Ind. Appl., Vol. 50, No. 3, pp. 1982-1993 (2014)

(5) P. W. Hammond, "A New Approach to Enhance Power Quality for Medium Voltage AC Drives", IEEE Trans. Ind. Appl., Vol. 33, No. 1, pp. 202-208 (1997)

(6) Y. Tadano, S. Urushibata, K. Ogura, A. Shigaki, and M. Nomura, "A Multilevel PWM Strategy suitable for High-Voltage Motor Direct Drive Systems in Consideration of the Adverse Effect of a Deadtime", IEEJ Trans. Ind. Appl., Vol. 126, No. 1, pp. 1-9 (2006)

(7) Y. Iwaji, T. Okuyama, D. Kaneko, and S. Okamatsu, "PWM Control Method suitable for High Voltage Multilevel Inverters", IEEJ Trans. Ind. Appl.., Vol. 121, No. 4, pp. 476-483 (2001)

(8) Y. Shoji, M. Nakashima, R. Ishii, and S. Kurozumi, "Development of Medium-Voltage PM Motors", MEIDEN REVIEW, Vol. 161, No.2, pp. 19-23 (2014)

(9) T. Tatsuta, H. Yamaguchi, and H. Kusunoki, "Development of New Model Medium Voltage multi-level IGBT Inverter", IEEJ Annual Meeting, 4-154, pp. 255-256 (2010)

(10) S. Furutani, and A. Satake, "Output Voltage Accuracy Improvement Method for Inverter to which Asynchronous PWM Applied", IEEJ J. Ind. Appl., Vol. 8, No. 6, pp. 997-1006 (2019)

(11) T. Daido, and Y. Hayashi, "Output Voltage Error Compensation for Every Half of a Carrier Period in a Voltage Source Inverter", IEEJ J. Ind. Appl., Vol. 8, No. 1, pp. 41-50 (2019)

(12) K. Nishizawa, J. Itoh, A. Odaka, A. Toba, and H. Umida, "Microcomputerbased Discontinuous PWM for DC-link Current Harmonic Reduction in Three-phase VSIs", IEEJ J. Ind. Appl., Vol. 8, No. 6, pp. 904-914 (2019)

(13) B. P. McGrath, C. A. Teixeira, and D. G. Holmes, "Optimized Phase Disposition (PD) Modulation of a Modular Multilevel Converter", IEEE Trans. Ind. Appl., Vol. 53, No. 5, pp. 4624-4633 (2017)

(14) I. Ouerdani, A. B. B. Abdelghani, and I. S. Belkhodja, "Harmonic Analysis of Pulse Width Modulation-Based Strategies for Modular Multilevel Converter", Int. J. Renew. Energy Res., Vol. 6, No. 3, pp. 838-846 (2016)

(15) K. Nishizawa, J. Itoh, A. Odaka, A. Toba, and H. Umida, "Input Current Harmonic Reduction based on Space Vector PWM for Three-level Inverter Operating over a Wide Range Power Factor", IEEJ J. Ind. Appl., Vol. 9, No. 3, pp. 208-218 (2020)

(16) A. Kawamura, S. Nakazaki, S. Ito, S. Nagai, and H. Obara, "Two-Battery HEECS Inverter with over $99.7 \%$ Efficiency at $2.2 \mathrm{~kW}$ Output and Measurement Accuracy Based on Loss Breakdown”, IEEJ J. Ind. Appl., Vol. 9, No. 6, pp. 663-673 (2020)

(17) S. Madhusoodhanan, K. Mainali, A. Tripathi, K. Vechalapu, and S. Bhattacharya, "Medium Voltage $(\geq 2.3 \mathrm{kV})$ High Frequency Three-Phase Two-Level Converter Design and Demonstration using $10 \mathrm{kV}$ SiC MOSFETs for High Speed Motor Drive Applications", IEEE Applied Power Electronics Conference and Exposition (APEC), pp. 1497-1504 (2016)

(18) K. Potty, M. A. Sabbagh, J. Pan, Z. Ke, J. Zhang, L. Xu, and J. Wang, "Performance Improvement of Medium Voltage Modular Multilevel Converter based Motor Drive using SiC MOSFETs", IEEE Applied Power Electronics Conference and Exposition (APEC), pp. 1189-1194 (2020)

(19) Z. Akhmetov, L. Chushan, W. Li, and A. Ruderman, "A Hybrid Three-Phase Seven-Level CHB Inverter with a Novel Modulation Scheme", IEEE Applied Power Electronics Conference and Exposition (APEC), pp. 2451-2454 (2020)

(20) D. Pan, D. Zhang, J. He, C. Immer, and M. E. Dame, "Control of MW-Scale High Frequency "SiC+Si" Multilevel ANPC Inverter in Pump-Back Test for Aircraft Hybrid-Electric Propulsion Applications", IEEE J. Emerg. Sel. Topics Power Electron., Vol. 9, No. 1, pp. 1002-1012 (2021)

(21) C. Li, R. Lu, C. Li, W. Li, X. Gu, Y. Fang, H. Ma, and X. He, "Space Vector Modulation for $\mathrm{SiC}$ and $\mathrm{Si}$ Hybrid ANPC Converter in Medium-Voltage High-Speed Drive System”, IEEE Trans. Power Electron., Vol. 35, No. 4, pp. 3390-3401 (2020)

(22) H. S. Patel, and R. G. Hoft, "Generalized Techniques of Harmonic Elimination and Voltage Control in Thyristor Inverters: Part I-Harmonic
Elimination”, IEEE Trans. Ind. Appl., Vol. IA-9, No. 3, pp. 310-317 (1973)

(23) T. Kato, and K. Iwamoto, "Optimum Pulse Pattern of Sinusoidal PWM Inverter with Filtering Effect", IEEJ Trans. Power Energy, Vol. 103, No. 4, pp. 235-242 (1983)

(24) M. Tsukakoshi, and K. Matsuse, "Method for Obtaining Fixed Pulse Pattern Suitable for Harmonic Regulation in Large-Capacity PWM Rectifier Systems", IEEJ Trans. Ind. Appl., Vol. 131, No. 3, pp. 380-387 (2011)

(25) J. Lago, and M. L. Heldwein, "Synchronous Optimal Pulsewidth Modulation Digital Implementation Concept for Multilevel Converters", IEEE Applied Power Electronics Conference and Exposition (APEC), pp. 2833-2839 (2016)

(26) J. Holtz, and N. Oikonomou, "Synchronous Optimal Pulsewidth Modulation and Stator Flux Trajectory Control for Medium Voltage Drives", Industry Applications Conference, pp.1784-1791 (2005)

(27) T. Geyer, N. Oikonomou, G. Papafotiou, and F. D. Kieferndorf, "Model Predictive Pulse Pattern Control", IEEE Trans. Ind. Appl., Vol. 48, No. 2, pp.663-676 (2012)

(28) A. Guerra, R. G. Rochin, and P. W. Cross, "Application of Model Predictive Pulse Pattern Control to Control a PMSM", IEEE Energy Conversion Congress and Exposition (ECCE), pp. 2238-2243 (2020)

(29) M. Vasiladiotis, A. Christe, and T. Geyer, "Model Predictive Pulse Pattern Control for Modular Multilevel Converters", IEEE Trans. Ind. Electron., Vol. 66, No. 3, pp. 2423-2431 (2019)

(30) W. Tian, Y. Pang, X. Gao, Q. Yang, and R. Kennel, "Computationally Efficient Optimization Method for Model Predictive Pulse Pattern Control of Modular Multilevel Converters", IEEE Energy Conversion Congress and Exposition (ECCE), pp. 5723-5730 (2020)

(31) N. Hartgenbusch, R. W. De Doncker, and A. Thünen, "Optimized Pulse Patterns for Salient Synchronous Machines", International Conference on Electrical Machines and Systems (ICEMS), pp. 359-364 (2020)

(32) T. Kumagai, T. Ito, K. Nishikawa, J. Itoh, K. Yamane, N. Yamada, and M. Nawa, "Reduction of Iron Loss in Stator Core using an Optimum Pulse Pattern for High-Speed IPMSM", IEEJ Trans. Ind. Appl., Vol. 141, No. 4, pp. 313-323 (2021)

(33) J. Lago, and M. L. Heldwein, "Generalized Synchronous Optimal Pulse Width Modulation for Multilevel Inverters", IEEE Trans. Power Electron., Vol. 32, No. 8, pp. 6297-6307 (2017)

(34) A. K. Rathore, J. Holtz, and T. Boller, "Synchronous Optimal Pulsewidth Modulation for Low-Switching-Frequency Control of Medium-Voltage Multilevel Inverters", IEEE Trans. Ind. Electron., Vol. 57, No. 7, pp. 2374$2381(2010)$

(35) A. K. Rathore, J. Holtz, and T. Boller, "Generalized Optimal Pulsewidth Modulation of Multilevel Inverters for Low-Switching-Frequency Control of Medium-Voltage High-Power Industrial AC Drives", IEEE Trans. Ind. Electron., Vol. 60, No. 10, pp. 4215-4224 (2013)

(36) M. Wu, H. Tian, Y. W. Li, and K. Wang, "A Novel Voltage Balancing Strategy for Four-Level Hybrid-Clamped Converters Under Selective Harmonic Elimination PWM", IEEE Energy Conversion Congress and Exposition (ECCE), pp. 2212-2218 (2020)

(37) J. E. Huber, and A. J. Korn, "Optimized Pulse Pattern Modulation for Modular Multilevel Converter High-Speed Drive", International Power Electronics and Motion Control Conference (EPE/PEMC), LS1a-1.4, pp. 17 (2012)

(38) A. Moeini, M. Dabbaghjamanesh, and J. W. Kimball, "Q-Learning-Based Smart Selective Harmonic Current Mitigation-PWM ( $\left.{ }^{2} \mathrm{HCM}-\mathrm{PWM}\right)$ for Grid-Connected Converters", IEEE Energy Conversion Congress and Exposition (ECCE), pp. 5068-5075 (2020)

(39) A. Testa, S. Foti, S. De Caro, L. D. Tornello, G. Scelba, and G. Scarcella, "Optimal Selection of the Voltage Modulation Strategy for an Open Winding Multilevel Inverter", IEEE Energy Conversion Congress and Exposition (ECCE), pp. 2231-2237 (2020)

(40) Y. Yamamoto, and Y. Ono, "V/F Control Method for Low Inertia PM Motor", IEEJ Industry Applications Society Conference, 1-56, pp. 247-250 (2005)

(41) J. Itoh, T. Toi, and K. Nishizawa, "Stabilization Method for IPMSM with Long Electrical Time Constant Using Equivalent Resistance Gain Based on V/f Control", IEEJ J. Ind. Appl., Vol. 8, No. 4, pp. $592-599$ (2019)

(42) R. Ogawa, M. Takiguchi, and Y. Tadano, "Multilevel Fixed Pulse Pattern Control for Medium-Voltage High-Frequency Inverter", International Conference on Electrical Machines and Systems (ICEMS), pp. 2089-2094 (2020) 
Ryuichi Ogawa (Member) received the B.E. degree from University

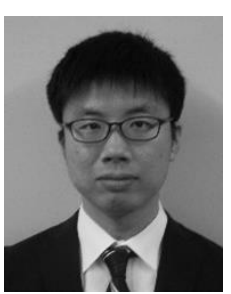

of Tokyo, Japan, in 2017. In 2017, he joined MEIDENSHA CORPORATION. He currently belongs to the Basic \& Core Technology Research Laboratories, $R \& D$ Group. He is engaged in research and development on power electronics. In 2019, he received the IEEJ Industry Applications Society Excellent Presentation Award.

Masashi Takiguchi (Member) received the M.E. degree from Kitami

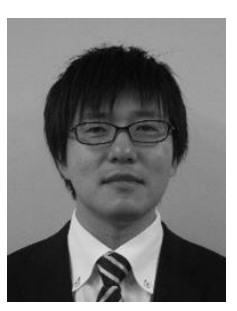
Institute of Technology, Japan, in 2008. In 2008, he joined MEIDENSHA CORPORATION. He currently belongs to the Basic \& Core Technology Research Laboratories, R\&D Group. He is engaged in research and development on power electronics.

Yugo Tadano

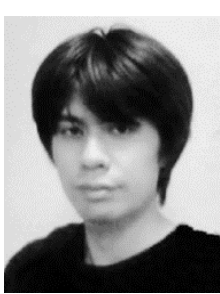

(Senior Member) received the M.E. degree from Mie University, Japan, in 2002. In 2002, he joined MEIDENSHA CORPORATION. He currently belongs to the Basic \& Core Technology Research Laboratories, R\&D Group. He is engaged in research and development on power electronics and measurement control technology. In 2006, he received an IEE Japan Best Paper Presentation Award. 